\title{
Application of static synchronous compensator and energy storage system for power system stability enhancement
}

\author{
Mohammed Salheen Alatshan ${ }^{1}$, Ibrahim Alhamrouni ${ }^{2}$, Tole Sutikno ${ }^{3}$, Awang Jusoh ${ }^{4}$ \\ ${ }^{1,2}$ Electrical Engineering Section, University Kuala Lumpur (UniKL BMI), Selangor, Malaysia \\ ${ }^{3}$ Department of Electrical Engeenering, Universitas Ahmad Dahlan, Yogyakarta, Indonesia \\ ${ }^{3}$ Embedded System and Power Electronics Research Group (ESPERG), Yogyakarta, Indonesia \\ ${ }^{4}$ School of Electrical Engineering, Universiti Teknologi Malaysia, Johor, Malaysia
}

\begin{tabular}{l}
\hline \hline Article Info \\
\hline Article history: \\
Received Mar 3, 2020 \\
Revised May 9, 2020 \\
Accepted Jun 15, 2020
\end{tabular}

Keywords:

Energy storage system

FACTS

Power stability

Power system

Smart grid

STATCOM

\begin{abstract}
The major drivers of the quest for optimal placement of flexible alternating current transmission system (FACTS) devices are the quest for smart grids and economic indicators. The demand for energy and power stability will continue much as the astronomic growth in industries and increase in global population remains. The aim of this paper is to deliver a panoramic view of the use of static synchronous compensator (STATCOM) in combination with energy storage system (ESS) in order to enhance power stability. In this paper, it was observed that application of ESS is an important factor in attaining power stability and mitigating the effect of dynamics associated with the power supply system. The miniaturization of batteries and adequate placement of STATCOMs will be a challenge much as new power system are built or existing ones are expanded. The future of ESS is towards the adoption of renewable energy sources as against batteries.
\end{abstract}

This is an open access article under the CC BY-SA license.

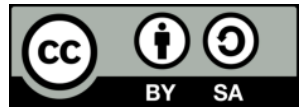

\section{Corresponding Author:}

Ibrahim Alhamrouni,

Electrical Engineering Section,

Universiti Kuala Lumpur-British Malaysian Institute,

Batu 8, Jalan Sungai Pusu, 53100, Gombak, Selangor, Malaysia.

Email: ibrahim.mohamed@unikl.edu.my

\section{INTRODUCTION}

Population and economic growth result in increase in the demand of electricity load type and capacity. Industrial and domestic expansions are few among other challenges of power quality. This in turn affect the reactive power and harmonic disturbances which constitute serious threat to the safe operation of power grid [1]. This results in electric power infrastructure that has served huge loads for so long and susceptive to many limitations. Out of many challenges it is to operate the power system in secure manner so that the operation constraints are fulfilled under both normal and contingent conditions. The break in energy supply called for smart grid technology and valuable techniques that can be deployed within the very near financial and technical constraints. Such technique must be effective for implementation to justify the time and financial implications [2].

The competitiveness nature of the energy market equally places heavy demand for load on the grid. This makes the grid to operate very close to its maximum capacity [3]. Therefore, congestions may occur due to unexpected line outage, generator outage, sudden increase of demand, and failures of equipment's. This made network congestion one of the major concerns for smart grids. Specifically, when a smart grid is implemented, it is possible to obtain measurements throughout the grid to identify and implement the necessary control actions in sub-second time frames. Thus, voltage instability and collapse that may lead to the blackout can be avoided, if suitable monitoring is used and application of a preventive control is taken. 
This is where the flexible AC transmission systems (FACTS) devices that have proffer solution to solve various power system problem comes handy [2].

While tracing the progress of power system and oscillation control techniques, the study conducted by Tyll and Schettler in [4] observed that, the milestones as presented in Figure 1. Where at point 1, between the years 1911 and 1929, only $110 \mathrm{kV}$ of power has been controlled and the result was conducted by Lauchhammer-Riesa, in a study conducted in Germany. In the second stage of the chart, it is clear that the system has been improved by the work conducted by Brauweiler-Hoheneck in 1929, which was able to manage $220 \mathrm{kV}$. In addition, the study conducted by Boulder Dam in 1932 revealed that the power management system was only able to handle $287 \mathrm{kV}$. The progress made was leveraged upon by the Harspranget-Halsberg study in Sweden in 1952. This was termed as the $4^{\text {th }}$ generation in the ladder of power system control, where the power output management ability increased to $380 \mathrm{kV}$. The latter study which was done in Montreal by Manicougan and was tagged as the $5^{\text {th }}$ generation on the ladder of harmonic management technology. In 1965, the manageable quantity of power was $735 \mathrm{kV}$. However, the quality has not been in the peak of what was expected. The value addition in the study conducted by Ekibastuz-Kochetav in Russia created a platform for the $6^{\text {th }}$ generation of power system management which manifested in 1985 . The energy stability system could handle about 1200 kvar. The above history reveals the background for the current situation and points towards the future [4]. In addition, consumers of electrical energy and its generation typically are not located in close vicinity. Large cities as well as large industrial areas are often supplied from distant located generation stations. The transmission of the power along a distance in the grid requires a stable system and voltage profile, which can only be maintained with the application of static synchronous compensator (STATCOM). This system is made of components of Var sources (capacitances, inductances) $[4,5]$.

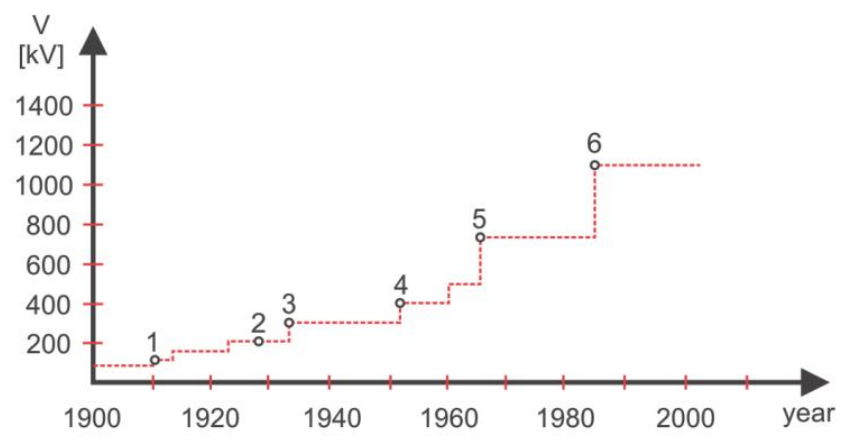

Figure 1. Increase of transmission system voltages over the years milestones [4]

Ma et al. [6] opined that quest was to control the reactive power in transmission and distribution. STATCOM, as an important member of the FACT, has gained acceptance and the attention of researchers more than ever. This system was listed as the state-of the-art dynamic shunt compensator. This system is built of sophisticated technology and excellent performances in smooth reactive power regulation and fast dynamic characteristics. This made it attract the interest of foreign and domestic electrical engineers in comparative with the traditional synchronous condenser. Hassan et al. [2] reported that the system was made public through a literature for the first time in 1989 when Narian Hingorani defined FACTS as "The concept of using solidstate power electronic devices mainly thyristor for power flow control at transmission level". The technology involved in the transmission of electrical power and electronic has advanced over a long period. Electricity transformation was to be done in order to derive the maximum benefit using flexible control systems in the energy storage. The earlier practice was to use the unreliable methods before the advent of this technology where a medium voltage (MV) or low voltage (LV) distribution networks is typically exercised through transformer tapchangers and/or switched capacitors/reactors. Lately, a STATCOM is used for fast and precise voltage regulation, especially for the sensitive/critical loads [7].

IEEE defined STATCOM as a self-commutated switching power converter supplied from an appropriate electric energy source and operated to produce a set of adjustable multiphase voltage, which may be coupled to an AC power system for the purpose of exchanging independently controllable real and reactive power. The controlled reactive compensation in electric power system is usually achieved with the variant STATCOM configurations. The STATCOM has been defined as per CIGRE/IEEE considering three operating structural components. First component is static: based on solid state switching devices with no rotating components; second component is synchronous: analogous to an ideal synchronous machine with 3 sinusoidal phase voltages at fundamental frequency; third component is compensator: provided with reactive compensation [6]. In literature, most of the methods proposed for sizing the FACTS devices only consider the

\footnotetext{
Application of static synchronous compensator and energy storage system... (Mohammed Salheen Alatshan)
} 
normal operating conditions of power systems. Consequently, some transmission lines were heavily loaded in contingency case and the system voltage stability becomes a power transfer-limiting factor [2]. To this end, an integration of ESS and STATCOM with two control loops including power-angle control and voltage control, which could exchange power flexibly and equally economically was reported to be a better option in the study conducted by Gao et al. [8]. The STATCOM based on voltage source inverter and battery energy storage system (BESS) formed an amalgamation of the STATCOM/BESS. When combining the two technologies, a three-phase structure [8] is applicable. However, the challenge of optimal placement and sizing of the STATCOM in combination with the battery storage device lingers. Energy storage system (ESS) can increase system reliability and dynamic stability, improve power quality and enhance transmission capacity of the transmission grid in a high power application [9]. A combination of short-term (cycles to seconds) energy storage integrated with a FACTS controller, was reported to be sufficient in high power application.

The areas of application of STATCOMs in the operation and control of a power grids are erroneous. It is used in schedule of power flow, reduction in the quantity of unsymmetrical components installed to damp power fluctuations. In addition, it support the stability of transient in the system $[10,11]$. When compensators are in operation, at times of generation shortfall or network constraint, the voltage of the non-critical loads is reduced while regulating the voltages across the critical loads. This addresses the generation shortfall or network constraint and also facilitates better voltage regulation of the critical loads through manipulation of the supply impedance voltage drop [7]. The relevance of the STATCOM when in operation is majorly to control the power system dynamics. This is achieved by providing a damping against power system oscillations. It equally extends to the damping of sub synchronous oscillations with the aim of providing balance in loading of individual phases. STATCOM also improve the transient stability margin and steadystate power transfer capacity; reduction of temporary over-voltages; and effective voltages regulation and control. Reduction of rapid voltages fluctuations were among other uses of the STATCOM [6, 12-14]. In addition, an ESS offers the following distinct advantages:

a. Provides system damping, while maintaining constant voltage following a disturbance.

b. It could control both active and reactive power simultaneously and independently.

c. It could charge batteries by absorbing active power from the grid.

d. It was rated higher because of multilevel topology.

e. It is capable and effective of damping the power oscillation.

f. It supports the system voltage during and after a disturbance [15].

g. Provides additional damping in situations where the dynamic reactive power provided by traditional FACTS controllers with similar ratings is inadequate.

h. Alternatively, it could provide the same amount of damping at less cost. Damping of oscillation, by repeatedly interchanging small amounts of real power with the system, would be an excellent ESS application.

i. Provides energy to maintain the speed of locally connected induction motors during a power system disturbance. This may prevent a voltage collapse in areas where there is a large concentration of induction motors that would otherwise stall [16].

\section{STATE-OF-THE-ART ON STATCOM}

Innovations targeted at achieving stability in the grid against the dynamics, voltage sourced converter (VSC) technology for reactive power compensation (RPC) and power surges had gone through developmental stages. Efforts were geared towards increasing system support in case of under voltages, higher speed of response to compensate flicker. The miniaturization of the design and easy reloadability, less harmonic interaction with the power system were also improved upon [15]. Today, there are different technical solutions on the market which may be summarized as multi converter concepts, high voltage PWM converters or multilevel converters [4, 17]. Due to the advantages for high power applications as aforementioned, multi-level converters have been introduced to FACTS to enhance power transmission system operation. Although several multi-level STATCOM topologies have been proposed to verify the high performance of multi-level converters used in reactive power compensation, they are not capable of controlling active power flow. To make multi-level converters more flexible and effective for active power flow control, energy storage systems are incorporated into STATCOM, such as flywheels and batteries [18] the inclusion of a battery to the storage system was tagged BESS.

\subsection{Generation of reactive power compensation; first generation}

The First Generation of reactive power compensators were the mechanically switched devices. They include: (i) Fixed shunt reactor (FR) [13], (ii) Fixed shunt capacitor (FC) [7], (iii) Mechanical switched shunt reactor (MSR) [19] and (iv) Mechanical switched shunt capacitor (MSC) [19, 20]. 


\subsection{The second generation}

The second generation of power compensators operate on a self-commutated solid-state voltage source inverter with the use of thyristor-based devices [15]. The identifiable categories are: (i) Thyristor controlled Reactor (TCR) [4], (ii) Thyristor switched capacitor (TSC) [4], (iii) Static Var compensator (SVC), (iv) Thyristor switched series compensator (Capacitor or reactors) (TSSC/TSSR), (v) Thyristor controlled series compensator capacitors or reactors (TCSC/TCSR), (vi) Thyristor controlled braking resistors (TCBR), (vii) Thyristor controlled phase shifting transformers, (viii) (TCPST), and (ix) Line commutated converter compensator (LCC) [12].

\subsection{Third generation power compensators}

With the shortcomings observed in the second generation of power compensators, the third generation was developed with emphasis on converting technology [13]. These include: (i) Converter-based devices, (ii) Static synchronous compensator (STATCOM), (iii) Static synchronous series compensator (SSSC) [12, 21], (iv) Unified power flow controller (UPFC) [21, 22], (v) Interline power flow controller (IPFC) [23] and (vi) Self commutated compensator (SCC) [12]. The improvement through the generations of the energy compensators had impact in the smooth delivery and compensation of losses along the grid, but was not sufficient in providing the optimum power compensation as a result of the complexity on the grid and supply system. The direction is towards automation and reliability. Basically, the research focus is on the STATCOM with the simple configuration as presented in Figure 2. Choosing the optimal location and size of the FACTS devices to get benefits in terms of improvement of voltage stability is a challenging task.

From this basic structure, different topologies of STATCOM have been proposed based on switching devices, the type of converter used and control applied for the STATCOM and its DC voltages [1]. The implication here is that several parameters affect the optimality and performance of the STATCOM. The works in [6] and [9] concentrated on switching devices. Converters in operation were studied by [24] and [25] while Du et al. [26], Muñoz et al. [15] and [20] concentrated on control in operation. Since the topology and other variables of the STATCOM are affecting the operations of the system in the power grid, it is important to establish a modus operandi aimed at having a realistic cost estimate, in order to do this, Chakraborty et al. [14] proposed the following steps for consideration.

a. First, system issue(s) to be addressed must be properly identified with specifications.

b. The information gathered will be used to study of preliminary system characteristics.

c. The basic energy storage, power, voltage, and current requirements would be identified and outlined.

d. A cost/effect of the system would be done to assess the financial benefits from the integration of thesystems to determine adequacy of utility's return on investment.

e. Model system performance in response to system demands to establish eff ectiveness of the energy support to be provided.

f. Optimize integrated system specifications and determine system cost.

g. A final comparative analysis of various energy storage systems are performance and costs.

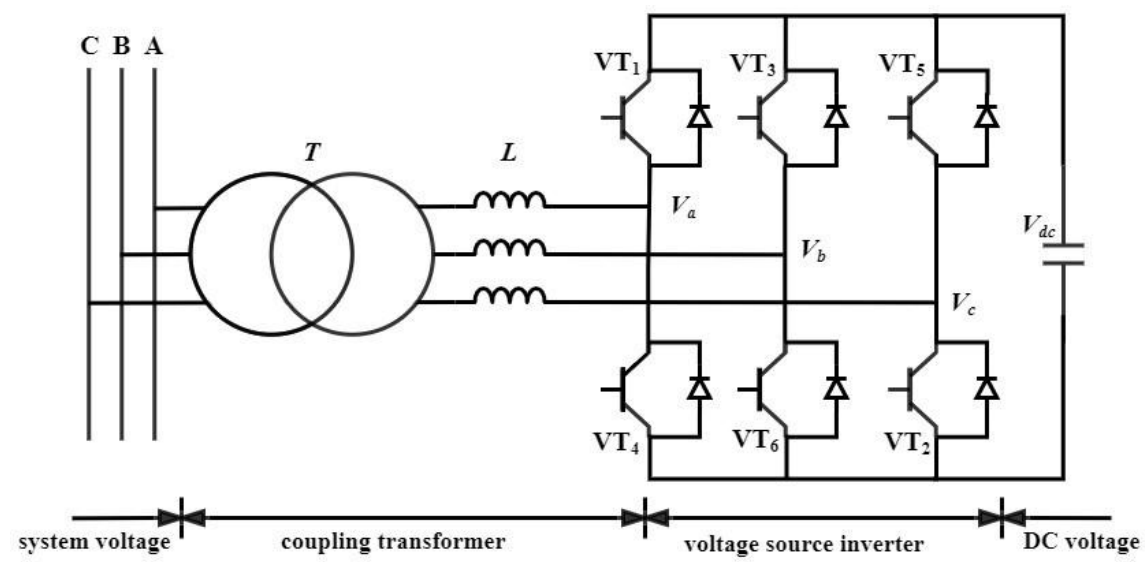

Figure 2. The basic structure of STATCOM [6]

Considering the aforementioned cumbersome process, the cost of conducting the assessments may be very expensive. In fact, the main challenge is the determination of the optimal size of STATCOM. Researchers' opinion was to simulate the process on a standard IEEE bus system. This opinion followedthe research conducted by Verayiah et al. [27-32]. Doing the simulation, it is expected that the bus with the weak 
link be determined for optimum intervention. In order to determine the optimal size of STATCOM which is optimally placed at the weak bus, various capacities of STATCOM in the range of 1 to 5 p.u. have been considered in the IEEE bus [33]. The practice was to transfer the result of simulation to the transmission line applications. Although, there are other FACTS, most studies concentrated on STATCOM because of the edges it has over others [4, 34]. However, the utilization of STATCOM technology alone may not be sufficient, since there is failure at intervals where energy back-ups are required. These backups may be informed of batteries and solar sources to serve as storage and augment for the expected losses or even absorb some excesses as a result of power surge.

\section{STATCOM+ESS CONNECTION}

The combination of a STATCOM and ESS presents a unique configuration to improve on the aforementioned advantages offered by STATCOM technology. The purpose of integrating ESS with STATCOM was to improve the resilience and efficiency of power delivery systems by employing advanced control, communications, and analytics Farraj et al. [20]. The drive for incorporation of ESS was to implement smart grid systems to facilitate the integration of energy resources and distributed storage. There are contemporary economical, technical, and environmental factors which have motivated growth in smallscale external ESSs that include both distributed generation and storage units. The appropriate integration of ESSs into power systems requires the study of suitable distributed control approaches [20]. The reason for this approach is to derive the maximum benefit from the power grids. A common approach for incorporating the ESS in modeling of control design is to use a first-order model for input-output modeling of ESS. This is represented in (1) with P ref and Q ref as the input. The circuit diagram is presented in Figure 3. During the modelling, the output power of the ESS is determined by changing these reference set points [35].

$$
\frac{P E S S}{\text { Pref }}=\frac{K p}{1+S T P}
$$

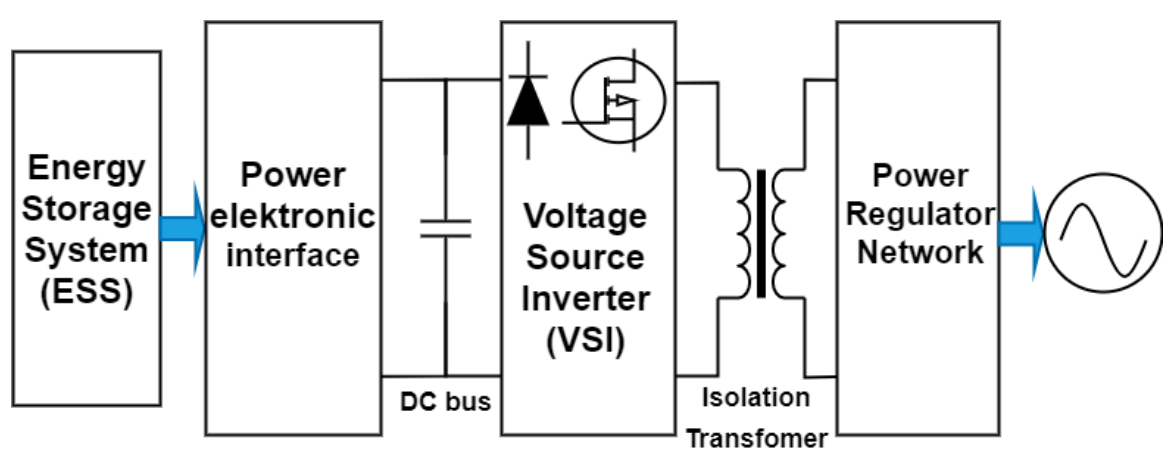

Figure 3. STATCOM + ESS connected to power utility system [14]

Rostami and Lotfifard [35] in their study proposed a control system based on the optimality condition decomposition (OCD) used in coordinating the subsystems. The study utilized actuators from mechanical power and field voltage controller of synchronous generator, and ESS which are able to provide synchronizing power support. After which, the performance of the proposed transient stability controller was studied using the New England 68-bus test system. They concluded that the simulation showed an effective to improve the angle stability of power systems subsequent to severe disturbances in the system. Turbine governor, ESS, and field voltage exciter of synchronous generators were used as actuators. Cheng et al. [34] studied the ESSs integrated with conventional and multi-level bidirectional power converters to be implemented on a hybrid STATCOM/ESS. The aim was to develop a conventional, diode-clamped, and cascaded multilevel converter-based STATCOM/ESSs and evaluate their performances for a variety of power system applications. A similar study conducted by Molina [36] modelled a dynamic DSTATCOM/ESS. Using the same multi-level control technique based on the instantaneous power theory on the synchronous rotating dq reference frame using simulations on the SimPower-Systems of MATLAB. The output of their validation and demonstration revealed that the system delivered a good performance of the multilevel controller as well as the benefits of its use in the distribution level power quality (PQ). This similar process was seen in the works of Balibani et al. [32], Hasan [37] used BESS is their simulation Farraj [20] strengthened the relevance of appropriate communication in the synchronization. 
One major challenge identified with the use of FACTS + ESS is the need for large set of batteries in order to integrate the FACTS with the size of the storage systems. This is peculiar to BESS, when considering implementation at the large-scale transmission-level applications. There are issues of voltage instability associated with large battery systems, occasionally. Moreover, placing numerous cells in series. However, typically it is seen that even large oscillations can be mitigated with modest power injection from a storage system. The ability to independently control both active and reactive powers in STATCOM + BESS makes them ideal controllers for various types of power regulation system applications, including voltage fluctuation mitigation and oscillation damping. Among them, the most important use of the STATCOM + BESS is to stabilize any disturbances occurring in the power system [14]. Rostami and Lotfifard [35] concluded in their study by projecting to the future with the need to develop a systematic approach for decomposition of power system into local subsystems and optimally sizing and locating ESS to provide ancillary services for stability improvement. The implication here is that there are gaps calling for optimal placement of ESS.

\section{ON THE USE OF ENERGY STORAGE SYSTEM (ESS)}

The deployment of STATCOM alone is not sufficient to attain the best point of stability in the power system. In the study conducted by [11], the STATCOM was combined with ESS to increase the level of stability using a small signal systems. This study was conducted on the computer simulation using a SMIB model equipped with a STATCOM-ESS combination [11]. The justification for the choice of a wind farm based permanent magnet synchronous generator (PMSG) using an AC/DC converter was to deliver the connection in an economically bearable manner. The report claimed that the combination of a standard STATCOM with ESS was an effective strategy. The modulation and control of both reactive and active powers were reported to be under proper check while the system was stable in terms of transient and dynamic limits. Fang et al. [11] conducted a study aimed at increasing the saturation-dependent stability of a power system fitted with an energy storage based damping controller (ESDC). The motivation of this study was to proffer as solution to the size required for an ESS while performing the same function. The limitation of ESS in power system was linked to the expensive initial cost of fitting an ESS device. When the capacity of an ESS can be increased, the cost may be reduced. The authors therefore designed a model of anti-windup compensator (AWC). The function of the AWC was to produce a signal using the response (differences) in output between the ESDC and saturated ESS. This action would supplement the signal to the ESDC and salvage the adverse effect of saturation.

The study adopted the reduced-order model of power system and linear matrix inequality in the design of the AWC. The process followed the development of a full fleche design process sing case studies which adapted the 4-machine 2-area power system and 10-machine New England power system [11]. In the work of Farraj et al. [20] a distributed control strategy was deployed due to the capacity it has for exploring the application of highly granular data for future power systems. The target was to improve the pliability of the system to perturbations. The focus was to study the effect of external ESSs to support the stability of the system due to fluctuations and the dynamics in the power system. This study also deployed the informationrich multi-agent framework solely using the ESS output control and a combination of linear feedback optimal (LFO) control to achieve transient stability. The process is information based, hence the signal to trigger the distributed ESSs for synchronous generators is activated through the LFO. The result revealed that the LFO controller when demonstrated using the 39-bus 10-generator New England test power system have a simple configuration. The system was simulated under the ideal and non-ideal conditions including communication latency, finite sampling rate, and sensor noise [20].

\section{DETERMINATION OF SIZING, PLACEMENT AND CONTROL OF STATCOM}

The beneficiation of the control and power stability system lies strongly and adequate determination of the placement and size of the STATCOM and the required ESS. There are researches done in this area where scalable wide area control scheme was demonstrated using distributed model predictive control (DMPC). The simulation proposed enhancement of the angle stability of power systems following large disturbances. In this regard, dynamic model of the local subsystems was the multi-area power system is developed for the model predictive controller and each subsystem is controlled by the associated controller. The controller of each subsystem exchanges minimum information with the controllers of neighboring subsystems to reach the final result [35].

The study by Hassan et al. [2] developed a technique for determining the proper rating/size of FACTS devices, namely the STATCOM. The case of contingency was the priority of the study. They utilized the eigenvalue and eigenvectors method in identifying the weakest bus placed the STATCOM at that location. The rating of STATCOM was specified according to the required reactive power needed to improve

Application of static synchronous compensator and energy storage system ... (Mohammed Salheen Alatshan) 
voltage stability under normal and contingency cases. Two case system studies were investigated: a simple 5-bus system and the IEEE 14-bus system. In another independent study conducted by Hassan [2], 5 and 14 buses were placed at different locations using the IEEE models to verify the validity of the proposed technique. The required STATCOM ratings, in both normal and contingency cases, were computed while the system operational constraints were maintained to have a secured system. The simulation produced results verifying the validity of the proposed technique in sizing the STATCOM [2]. In addition, Sirjani [38] studied an optimum location of PV-STATCOM, but not the sizing of ESS. The author used empirical data from solar irradiance, solar power generation data and load data for 8760 hours in a year for the study. The target was to deploy photovoltaic energy as a source of surge in the grid. The author concluded that the problem of optimal PV-STATCOM placement and sizing in both transmission and distribution systems considering the effect of harmonics and system dynamic support should be evaluated in the future research [38].

Chakraborty et al. [14] in a review on the methodology of integrating STATCOM and BESS for power system transient stability adopted the use of MATLAB/Simulink modeling for the placement and control of the integration of a STATCOM with a battery. The research also considered the dynamic response to generator rotor angle oscillations as a result of a 3-phase fault. They opined that the STATCOM-battery combination could be very eff ective in compensating generator rotor angle oscillations and thus well suited for improving transient stability and the dynamic behavior of the power system. Rafi [37] demonstrated the use of multi-operations with a single stage transformer less voltage source inverter (VSI). The study adopted the AC-DC microgrid while controlling the process of active power from a photovoltaic (PV) system. The energy source was made to rectify fluctuations due to DC loads, performs VAR compensation obtainable in the STATCOM configurations. Through the process, the design targeted shrink in voltage and power oscillation as STATCOM/ESS. It was assumed that the photovoltaic source of energy fluctuates due to sudden radiation changing, random load changing, and different faults effects. The power system computer aided design (PSCAD) was used in conducting the performance assessment on a micro grid model.

Munoz et al. [15] used a combination of four representative control techniques to study a cascaded H-Bridge STATCOM. They opined the use of Static and dynamic simulations would expose more information on the challenges and main advantages of each scheme. While juxtaposing the hysteresis and predictive control alongside the carrier-based strategies, it was reported that the latter is preferred in terms of switching harmonics and relevant in design of filter. Whereas, the former result in unpredictable harmonics, which can cause unexpected resonances that could be harmful. In a study conducted by Sirjani [38], the proposed method employed for optimal PV-STATCOM placement and sizing was based on empirical data. The data adopted was the power loss index in conjunction with the adaptive particle swarm optimization (APSO). The result turned out that the APSO performed better in finding optimal solutions. Beyond that, the APSO equally converged faster compared with bee colony optimization (BCO) and the lightening search algorithm (LSA), two methods that were used to validate the performance of APSO.

\section{STATCOM COMPUTATION ALGORITHMS AND CONTROL TECHNIQUES}

By design, the STATCOM is meant to operate principally in order to consume the reactive power from the power system based on the converter controls and the expected value of voltage to be handled by the grid. When in operations, the STATCOM module regulates between the inductive and capacitive load to control the reactive power. Here, when the voltage is higher than the target, STATCOM operates in an inductive mode to absorb the reactive power [39]. In a study conducted by Muñoz [15] a unique technique was developed for the control of the current with particular consideration for a cascade H-Bridge STATCOM. The paper assessed four different methods which include the linear strategy using proportional integral controllers in the dq frame, an exact input/output linearization technique with proportional-resonant controllers, a multiband hysteresis modulation control, and a predictive control scheme. The simulations were done using the PSim 9.0 software, for a 7-level CHB-STATCOM. The capability of the DSTATCOM was also demonstrated using the PSim for validation in the study conducted by Singh [40]. In recent times algorithms such as the genetic algorithm (GA) and evolutionary programming were tested in delivering the optimal allocation as well as the types of devices and their sizes using the evolutionary computation techniques to allocate FACTS devices. The results obtained were favorable in providing solutions. The study conducted by Karthikeyan [41] adopted the particle swarm optimization (PSO) which is another evolutionary computation technique in assessing the performance of PSS with STATCOM in combination with 9 bus system and the power system analysis tool box (PSAT) software. The PSO algorithm was established for optimal location of STATCOM. The PSO was also deployed in some power engineering problems like the economic dispatch [42].

Another emerging optimization technique is the heuristic optimization techniques. This technique has been used in the optimal placement and sizing of SVC and STATCOM. The method is gaining better 
acceptability in proffering quality solutions to the complex and sophisticated problems of sizing and placement of STATCOM, which are otherwise difficult to solve by traditional methods [43]. The contemporary heuristic optimization technique was an improved version of the global optimization algorithms developed based on population estimation requirements using nature inspired analogy [9]. Another name for this type of algorithm is the general purpose algorithms because of their applicability to a wide range of problems [44]. On the list of heuristic algorithms popular are the Ant colony optimization which was used by Fughar and Nwohu [45] in placement of STATCOM parameters and probabilistic model in delivering a solution to the challenges of STATCOM placement on Nigerian grid. In [46], Ant lion optimizer which was developed following the hunting mechanism of ant lions in nature. Artificial bee colony (ABC) algorithm was used in the study conducted by [33]. Bat algorithm was used in the two-degree-of-freedom fractional order PID (2-DOF-FOPID for optimization of STATCOM placement [47]. Other algorithms include the Cat swarm optimization [50], Crow search algorithm [49], Cuckoo optimization algorithm, Cuckoo search algorithm, Differential evolution, Firefly algorithm, Genetic algorithm, Glowworm swarm optimization, Gravitational search algorithm, Grey wolf optimizer, Harmony search, Multi-verse optimizer, PSO, Shuffled complex evolution, Simulated annealing, Tabu search, and the Teaching-learning-based optimization [50]. As aforementioned, the placement and optimization of STATCOM has received attention from different kinds of algorithms. The research conducted by Nusair [50] made a comparative analysis with other techniques such as PSO, differential evolution (DE) and a host of eight other algorithms using the IEEE 14-bus and modified IEEE 30-bus power systems. The report revealed that other techniques were equally competitive, but the choice of a particular technique is a function of the desired damping capacity required [26], transfer ability, small signal steadiness and steady state stability boundary [51].

\subsection{The evolution strategies (ES)}

This is an optimization method that emerged as a result of a research conducted in the University of Berlin in Germany in the 1960s. The technique attracted the attention of scholars who expanded the original concept by Rechenberg and Schwefel in the 1970s. The main idea was used in delivering optimum solutions in the field of hydrodynamics. The expansion in the capability of this strategy has gained a place for it in the provision of solutions to multi-dimensional, complex optimization problems [52]. In the study conducted by [44] the method was reported to be used for placement of STATCOM. The optimization strategy launces a search on all possible solution points through mutation operator. Solution candidates are selected from one search point to another. A parent strategy, designated by $1+1$, creates one offspring from a single parent by applying mutation. The offspring replaces the parent for the next generation if it outshines the parent during the search. This principle was also implemented in locating the optimum points of operation for FACTS devices. The model is usually adjusted using the objective function as boundary conditions for the STATCOM, and UPFC in order to improve the power system operation. This was done by decreasing losses in the power grid. The model was applied to some power systems and was reported to be effective with some degree of optimum placements and low computational effort.

\subsection{Genetic algorithm (GA)}

In the report compiled by Valle [42], GA was reported to be used in optimum placement of FACTS devices with favorable results. Three basic operators called as selection, recombination or crossover and mutation are employed in the process [19]. The technique it gaining acceptance lately as an evolutionary algorithm. The method rely on a set of computing model used in mimicking natural and genetic selection like was done in the case of Darwin's Theory using evolution of genetics in biology [43]. When in operation, solution candidates in form of population serve as representatives of the desired result like in the case of chromosomes or the genome of candidate solutions. These are referred to as individuals. The computing process represent them as binary strings contained of $0 \mathrm{~s}$ and $1 \mathrm{~s}$ with fixed length. However, the encoding can be modified to real values called chromosomes. By default, digits are allocated to these chromosomes in form of bits and coding. The program commences by stochastically initialization of population as obtainable in the evolutionary computation principles. As aforementioned, this technique is also linked to Particle swarm optimization [53]. The technique is equipped with implicit parallelism which augments the ability to conduct iterations and make it fast in proffering solutions to complex optimization problems [54]. For appropriate selection, entities are chosen from the current population for later breeding (recombination or crossover). For optimization, potential options get selected using the individual's fitness value. Some of the fitness test methods include the tournament selection and fitness proportionality selection which is also known as roulettewheel selection [46]. On the other hand, an arbitrary constant may be allocated as a limit for fitness of individuals. The implication is that any candidate option with a fitness value less that the arbitrarily allocated constant gets rejected. The duo is called reproduction as obtainable in biology. This was used in optimal placement of only one SVC targeted at reducing power loss in a power grid. It was equally deployed for voltage deviation and cost [55].

Amiri et al. [19] used the GA in determining the suitable location and capacity of the STATCOMs for improvement in the voltage characterization of a network using wind farms as distributed generation. Also, the stochastic behavior of the wind speed has been considered to approach the actual condition of the wind

Application of static synchronous compensator and energy storage system... (Mohammed Salheen Alatshan) 
generation. The report compared three different cases using simulation. It was observed that the use of a single STATCOM improved the voltage profile, though it was not sufficient. Therefore, a GA based optimization procedure was successfully implemented to find the best placement, type, and size of selected FACTS devices for reducing losses in the network caused by voltage sags. The study conducted by [56] adopted the GA with the IEEE 14-bus system in determining the best options in locating energy storage devices for system voltage stability. The work separated the optimization of controller parameters in a predefined manner, therefore optimized parameters differently before the locations. In addition, GA was used in considering SVC, STATCOM, and dynamic voltage restorer (DVR) as types of FACTS. The study adopted the power system stability as an index for optimal allocation of the controllers. The simulation commenced by optimally placing different SVCs in a power system using modal analysis in combination with a GA. The implication was to determine the best position before controlling the fluctuations. The parameter used in the placement was the primary function of SVCs.

The selection followed the most suitable input signal associated with auxiliary controller. The optimum input signal was used in identifying the frequency response characteristics of the system. GA was reported to be appropriate in economic consideration of placement of FACTS devices [46]. In a study by Huang et al. according to [6], a Messy-GA technique was introduced and modelled in the determination of optimal placement of SVC in a power system. The study utilized multi objective optimization in in order to maximize the worst-case reactive margin. Other parameters considered were highest load voltage at the critical operating point, minimum power losses and lowest device cost. This modified algorithm was equally deployed in identification of suitable profiles for voltage stability enhancement of power systems under critical operation conditions. The practice was to generate a multi-objective optimization function and convert these set of options to a fuzzy decision problem using a single objective function. The single objective function would then be disintegrated into two sub-problems. The process of demining the best placement of FACTS devices usually commence by conducting an all-inclusive assessment of the most critical operating condition of the system. By extension, all constraints and nonlinear effects were considered. The search for optimality would then commence from the main sub-problem with the objective of identifying an optimal SVC reinforcement that augments the SVC efficiency. To commence a search step of the GA, the Lagrange multiplier techniques are used to solve the second sub-problem. When in operation, the messy GA considers the placement of only one FACT device and the efficiency of the simulated grid would be assessed using voltage variance and loss in power generation reduced in the electricity network. This method was adopted in the research reported in $[57,58]$.

\subsection{Queen bee assisted GA}

Queen Bee is a modified version of the GA where FACTS devices are placed in optimal locations in order to improve on their voltage profile. This algorithm deployed a technique integrating the advancement of a queen bee in a hive. The edge it has over the conventional GA was that it converges faster. The parameters are reduced and time spent in computation are cut shorter with optimum solutions provide at lower cost. Voltage stability index was adopted for assessing the performance benchmark at any given bus. Simulation results would then be used to validate the efficiency of the Queen bee assisted algorithm. This method was used in identification of optimum location for placing FACTS devices in a research conducted by Sundareswaran et al. [59]. The aim was to improve on the voltage features of the network. The result proved that the Queen Bee techniques was faster in comparative to traditional GA.

\subsection{The non-dominated sorting genetic algorithm (NSGA)}

The study conducted by Benabid et al. [32] as reported in the findings of Dubey [44] used a NSGA-II in obtaining an optimum two adversary objective function comprising of the real and reactive power losses and absorbed by the generator and SVC. The technique considered the security and economic features of the system. The experiment proposed the adoption of a Fuzzy-GA logic method to support the process of decision making in selecting an optimum solution. This was done with the provision of alternatives from non- dominated solution of Pareto front. The experiment adopted the Italian power system model. In another study, the NSGA was adopted in continuous, discrete, and multiple placements of five Mvars of compensator devices using the IEEE 57-bus test system [60]. For proper implementation of the NSGA, the optimum challenges were scheduled in form of multi-objectives criteria. The parameters considered include the active power losses, compensation maneuvers like SVC and TCSC were deployed. It turned out that the set of outputs obtained were evenly distributed and had satisfactory range characteristics.

GA was also applied for solving both the inter-area congestion and oscillation issues in a high voltage transmission system by installing FACTS devices [32]. The algorithm considered a multi-objective approach and two FACTS devices, namely SVC and TCSC. The multi objective optimization was studied for a wide range of weights on the objective functions. Simulation outcomes were reported to be promising in providing requisite information for the system operator to make correct decisions using the GA criteria. The development of an average circuit model used in the control of STATCOM with the aid of angular placement was done using the GA. The process used in determining the power flow for the system $[3,12]$ reported the findings of 
Tavakoli et al. The focus of the study was on voltage stability using an amalgamation of optimization processes. Parameters like reactive power, and losses of transmission lines were also part of the aim of the optimization performed on the system. There are indications from the study of [55] that the utilization of GA in sizing and placement of STATCOM using the IEEE 14-bus network delivered a good result. The process was to specify a power ration to be used in comparing the optimized value with the average model. The technique deployed a combination of sensitivity analysis with the GA for appropriate placement of the STATCOM within a distribution network. Using a sequential process, a sensitivity study was conducted to determine the best location and for FACTS devices in providing compensators. This sensitivity would then be deployed in identifying compound voltage-loss sensitivity index for the purpose of using it for different optimization requirements. After that, additional process in determining the power required to be injected by the STATCOM would be specified by the GA.

\subsection{Simulated annealing (SA)}

The simulated annealing (SA) is one of the flexible techniques used in proffering solution the placement of FACTS devices. The principle relies on a combination of the relationship between statistical mechanics and optimization. This technique was reported to be capable of being used in large-scale systems irrespective of the basic requirements for conventional optimization process such as differentiability, continuity, and convexity. The emergence of SA was traced back to the early 1950s when the Metropolis developed this model for application in the crystallization process. As the name implies, annealing means melting the system to be optimized firstly at a high temperature. The next step was to reduce the temperature of the system and allow it to cool down slowly by lowering the temperature while the system freezes and no further change occurs. For every annealing cycle to be completed, the process must be allowed to continue for long enough until the system reach a steady state.

A method based on the SA and Lagrange multiplier techniques for optimal placement of SVCs was presented in [35]. A four-step procedure was proposed for synthesizing the optimal reactive reinforcement for a selected design configuration. The procedure maximized the reactive margin of a design configuration as the criterion. The optimal SVC placement was realized by solving two sub problems. The SA performed a search for the optimal SVC reinforcement which maximized the reactive margin of the power system. Gitizadeh and Kalantar proposed an approach based on SA and sequential quadratic programming (SQP) in the optimization process for optimally locating TCSC and SVC [36]. The problem was formulated according to the SQP problem in the first stage to accurately evaluate the static security margin with the congestion alleviation constraint in the presence of FACTS devices, and in the next stage a SA based optimization technique was used to find an optimal solution. The simulation results showed that this placement approach reduced congestion in the transmission lines and enhanced distance of the voltage collapse point without the use of procedures with a high computational burden such as the CPF method.

\subsection{Particle swarm optimization (PSO)}

The PSO is a kind of evolutionary computation algorithm used in proffering solutions to global optimization problems. The emergence of the PSO algorithm was traced back to 1995 when it was deployed for delivering solutions to optimization challenges by Eberhart and Kennedy. The technique has gained acceptability as a solution tool used by various researchers. The method searches for optimum result and had been deployed for various applications which include hybridization and specialization. This method has shown good performance in a variety of application domains. It is a simple and robust strategy based on the social and cooperative behavior shown by various species like flocks of bird, schools of fish, and so on.

\subsection{Harmony search (HS) algorithm}

The foundation of this algorithm was on the basis of the principles adopted by the musicians. While the musician attempts to discover a suitable and optimal instrumental pitch, the experience of the players and the instrument in use are combined to deliver the optimum harmony. This concept was borrowed to the computing field. The implication is that to deliver an optimum solution, the computational professionalism of the user is required in obtaining optimal design variables with certain discrete values based on computational intelligence and random processes. Music players improve their experience based on aesthetic standards while design variables in computer memory can be improved based on an objective function. This algorithm has an edge over other techniques in that it can consider both discontinuous and continuous functions because it does not require differential gradients, it does not require initial value setting for the variables, it is free from divergence, and it may escape local optima.

\subsection{Hybrid artificial intelligence techniques}

An amalgamation of two or even more artificial intelligence system is required to deliver a hybrid intelligent system. Two major steps involved in developing the hybrid technique are the fuzzy logic. The aim of this step was to reduce the search space. The second stage is the use of micro-GA. This could only recognize predetermined buses. This technique was applied in proffering solution to engineering issues during the last 
decade. The application of this technique was deployed in the optimization of various process parameters involving four different FACTS devices such as the TCSC, TCPAR, UPFC, and SVC in a power system.

\section{FUTURE TECHNOLOGY}

More reactive power compensation (RPC) installations are probably required in the near future to overcome system limitations which is seen an important contribution to increase system stability and prevent blackouts [4]. For a given range of supply voltage variation, the total voltage regulation and the total reactive capacity required for each option to produce the desired voltage regulation at the point of connection are expected to be better. The future holds that advancement may require less overall reactive power capacity than STATCOM and yields better total voltage regulation. This makes electric springs (ESs) a promising technology for future smart grids where selective voltage regulation for sensitive loads would be necessary alongside demand side response [7]. Further it is stated that the energy storage technology will be the key to the future development of renewable energy. In [5] some of the commercial successes in electric power storage technologies have been discussed and it also discusses some of the emerging applications in power storage like wind farm power stabilization. The report [6] provides a catalogue of the various current technologies (steam, hydro, wind, etc., and storage being one of them). Their future outlooks, evaluations of security of supply and environmental impacts, climate change evaluations, and technical and economic analysis, in the context of energy planning activities.

\section{CONCLUSION}

Currently, the accessible technology has limitations in identifying the optimal sixing and placement of the STATCOM and ESS. A handful of studies adopted a basic algorithm and make modifications to suite the demand of the power system understudied. The deployment of various methods of reducing the effect of dynamics on the power system revealed that the battery still remains one of the popular methods of attaining stability in the system. The proposed wind, solar, renewable sources of energy are still at the infancy stage. The development of all algorithms was based on profounder theories that were later adapted to the field of power, engineering, and the placement of FACTS devices. Obviously, the process of placement, sizing and locations of STATCOMs will continue to be a challenge because power systems will keep evolving with time. It is clear from the review that the maximum beneficiation of the use of STATCOM in combination with ESS remains unexhausted. The power dynamics remains a challenge to be solved only by the use of STATCOM in combination with ESS. It is obvious that STATCOM applications are often simulated on the systems of MATLAB. There is equally the fear of implementation of the STATCOM with ESS using batteries. These challenges will be surmounted with the miniaturization of battery cells and development of high capacity batteries. In fact, when these technologies are fully blown, the challenges of power fluctuations and the dynamism will be well controlled.

\section{REFERENCES}

[1] O. K. Shinde and V. R. S. V. B. Pulavarthi, "STATCOM converters and control: A review,"2017 International Conference on Data Management, Analytics and Innovation (ICDMAI), Pune, pp. 145-151, 2017.

[2] H. A. Hassan, Z. H. Osman, and A. E. Lasheen, "Sizing of STATCOM to Enhance Voltage Stability of Power Systems for Normal and Contingency Cases," Scientific Research Open Access, vol. 5, no. 1, pp. 8-18, 2014.

[3] E. Ghahremani and I. Kamwa, "Optimal Allocation of STATCOM with Energy Storage to Improve Power System Performance," 2014 IEEE PES T\&D Conference and Exposition, Chicago, IL, pp. 1-5, 2014.

[4] H. K. Tyll and F. Schettler, "Historical overview on dynamic reactive power compensation solutions from the begin of AC power transmission towards present applications," 2009 IEEE/PES Power Systems Conference and Exposition, Seattle, WA, pp. 1-7, 2009.

[5] H. Musa, "An Overview on Voltage Stability Indices as Indicators of Voltage Stability for Networks with Distributed Generations Penetration," International Journal of Science, Technology and Society, vol. 3, no. 4, pp. 214-219, 2015.

[6] Y. Ma, A. Huang, and X. Zhou, "A review of STATCOM on the electric power system," 2015 IEEE International Conference on Mechatronics and Automation (ICMA), Beijing, pp. 162-167, 2015.

[7] S. Shankari, "Comparison of Electric Springs with Statcom for Flc Based Distributed Voltage Control," International Journal of Profesional Engineering Studies, vol. VI, no. 3, pp. 355-362, 2016.

[8] K. Gao, L. Yuan, Z. Zhang, and L. Li, "The Study of STATCOM-BESS Damping Power System Oscillations based on DTA Method," DEStech Transactions on Computer Science and Engineering, no. iccae, pp. 418-422, 2017.

[9] R. Sirjani, A. Mohamed, and H. Shareef, "Optimal placement and sizing of shunt FACTS devices in power systems using heuristic optimization techniques: A comprehensive survey," Przeglad Elektrotechniczny, vol. 88, no. 10b, pp. 335-341, 2012. 
[10] U. Datta, A. Kalam, and J. Shi, "Battery energy storage system for transient frequency stability enhancement of a large-scale power system," 2017 Australasian Universities Power Engineering Conference (AUPEC), Melbourne, VIC, pp. 1-5, 2017.

[11] J. Fang, W. Yao, Z. Chen, J. Wen, and S. Cheng, "Design of anti-windup compensator for energy storage-based damping controller to enhance power system stability," in IEEE Transactions on Power Systems, vol. 29, no. 3, pp. 1175-1185, May 2014.

[12] B. Singh, R. Saha, A. Chandra, and K. Al-Haddad, "Static synchronous compensators (STATCOM): A review," IET Digital Library, vol. 2, no. 4, pp. 297-324, July 2009.

[13] T. Masood, R. K. Aggarwal, S. A. Qureshi, and R. A. J. Khan, "STATCOM Model against SVC Control Model Perfomance Analyses Technique by MATLAB," International Conference on Renewable Energies and Power Quality (ICREPQ'10), 2010.

[14] A. Chakraborty, S. K. Musunuri, A. K. Srivastava, and A. K. Kondabathini, "Integrating STATCOM and Battery Energy Storage System for Power System Transient Stability: A Review and Application," Advances in Power Electronics, vol. 2012, no. 676010, 2012.

[15] Chapter 5, “Active Power Compensation Of Statcom With Energy Storage System” pp. 167-206, 2003.

[16] J. Muñoz, J. Rohten, J. Espinoza, P. Melín, C. Baier, and M. Rivera, "Review of current control techniques for a cascaded H-Bridge STATCOM," 2015 IEEE International Conference on Industrial Technology (ICIT), Seville, pp. 3085-3090, 2015.

[17] Lirong Zhang, Yi Wang, Heming Li and Pin Sun, "Hybrid power control of cascaded STATCOM/BESS for wind farm integration," IECON 2013-39th Annual Conference of the IEEE Industrial Electronics Society, Vienna, pp. 5288-5293, 2013

[18] Chang Qian and M. L. Crow, "A cascaded converter-based StatCom with energy storage," 2002 IEEE Power Engineering Society Winter Meeting. Conference Proceedings (Cat. No.02CH37309), New York, NY, USA, pp. 544-549 vol.1, 2002.

[19] E. M. Amiri, B. Zaker, H. Rahbarimagham, and M. Abedi, "Optimal Placement and Sizing of STATCOM to Improve Power Quality Considering Wind Generation," The Third Iranian Conference on Renewable Energies and Distributed Generation, 2013.

[20] A. Farraj, E. Hammad, and D. Kundur, "On the use of energy storage systems and linear feedback optimal control for transient stability," in IEEE Transactions on Industrial Informatics, vol. 13, no. 4, pp. 1575-1585, Aug 2017.

[21] M. Salman, "STATCOM Controller ( Design and Assessment ) for Transmission and Distribution System Problems," International Knowledge Sharing Platform, vol. 7, no. 8, pp. 30-45, 2016.

[22] K. Joshi and V. Chandrakar, "Transient Stability Improvement using UPFC-SMES in a Multi Machine Power System," International Journal of Applied Power Engineering IJAPE, vol. 5, no. 1, pp. 14-21, April, 2016.

[23] D. Shen and P. Lehn, "Modeling, analysis, and control of a current source inverter-based STATCOM," IEEE Transactions on power delivery, vol. 17, no. 1, pp. 248-253, 2002.

[24] H. H. Goh, Q. S. Chua, S. W. Lee, B. C. Kok, K. C. Goh, and K. T. K. Teo, "Line Voltage Stability Indices Based on Precautionary Measure Approximation in Smart Grid," Proceedings of the $11^{\text {th }}$ International Conference on Innovation \& Management, pp. 1507-1518, 2014.

[25] Y. Suresh and A. Panda, "Statcom Operation Strategy Under Single Line to Ground Faults in Power System," 2010.

[26] W. Du, Z. Chen, H. F. Wang, and R. Dunn, "Energy storage systems applied in power system stability control," 2007 42nd International Universities Power Engineering Conference, Brighton, pp. 455-458, 2007.

[27] R. Verayiah, A. Mohamed, and H. Shareef, "Modified Novel Line Stability Factor Index with Reactive Power Tracing for Identification of Vulnerable Buses in Power System Modified Novel Line Stability Factor Index with Reactive Power Tracing for Identification of Vulnerable Buses in Power System," Applied Mechanics and Materials, vol. 785, pp. 398-402, 2015.

[28] S. Sao, "Voltage Stability Indicator At The Proximity Of The Voltage Collapse Point And Its Implication On Margin," Citeseer, vol. 5, pp. 151-154, 2011.

[29] M. Stuchl, S. Misak, and L. Prokop, "A simulation of energy storage system for improving the power system stability with grid-connected pv using MCA analysis and labview tool," Power Engineering and Electrical Engineering, vol. 13, no. 2, pp. 127-136, 2015.

[30] D. Hemasundar, M. Thakre, and V. Kale, "Impact of STATCOM on distance relay-Modeling and simulation using PSCAD/EMTDC," in 2014 IEEE Students' Conference on Electrical, Electronics and Computer Science, pp. 1-6, 2014.

[31] H. Ahsan and M. U. D. Mufti, "Modeling and simulation of a superconducting magnetic energy storage based multi-machine power system for transient stability study," 2017 6th International Conference on Computer Applications In Electrical Engineering-Recent Advances (CERA), Roorkee, pp. 347-352, 2017.

[32] S. K. Balibani, G. Gurrala, and I. Sen, "Power system stability enhancement using a STATCOM with ESS," 2013 Annual IEEE India Conference (INDICON), Mumbai, pp. 1-6, 2013.

[33] A. S. Telang and P. P. Bedekar, "Systematic approach for optimal placement and sizing of STATCOM to assess the voltage stability," 2016 International Conference on Circuit, Power and Computing Technologies (ICCPCT), Nagercoil, pp. 1-6, 2016.

[34] Y. Cheng, C. Qian, M. L. Crow, S. Pekarek, and S. Atcitty, "A comparison of diode-clamped and cascaded multilevel converters for a STATCOM with energy storage," in IEEE Transactions on Industrial Electronics, vol. 53, no. 5, pp. 1512-1521, Oct 2006.

[35] M. Rostami and S. Lotfifard, "Scalable Coordinated Control of Energy Storage Systems for Enhancing Power System Angle Stability," in IEEE Transactions on Sustainable Energy, vol. 9, no. 2, pp. 763-770, April 2018. 
[36] M. G. Molina and P. E. Mercado, "Control design and simulation of dstatcom with energy storage for power quality improvements," 2006 IEEE/PES Transmission \& Distribution Conference and Exposition: Latin America, Caracas, pp. 1-7, 2006.

[37] F. H. M. Rafi, M. J. Hossain, and J. Lu, "Design of a single stage transformerless VSI in a smart microgrid for PVSTATCOM/ESS operations," 2014 Australasian Universities Power Engineering Conference (AUPEC), Perth, WA, pp. 1-6, 2014.

[38] R. Sirjani, "Optimal Placement and Sizing of PV-STATCOM in Power Systems Using Empirical Data and Adaptive Particle Swarm Optimization,” Sustainability, vol. 10, no. 3, p. 727, 2018.

[49] A. M. Eltamaly, Y. Sayed, A. M. El-sayed, A. Nasr, and A. Elghaffar, "Adaptive static synchronous compensation techniques with the transmission system for optimum voltage control," Ain Shams Engineering Journal, vol. 11, no. 1, pp. 35-44, March 2020.

[40] R. Singh and D. K. Singh, "Simulation of D-STATCOM for Voltage Fluctuation,"2012 Second International Conference on Advanced Computing \& Communication Technologies, Rohtak, Haryana, pp. 225-230, 2012.

[41] K. Karthikeyan and P. K. Dhal, "ScienceDirect Optimal Location of STATCOM based Dynamic Stability Analysis tuning of PSS using Particle Swarm Optimization," Materialstoday Proceedings, vol. 5, no. 1, pp. 588-595, 2018.

[42] Y. Valle, S. Member, J. C. Hernandez, S. Member, and G. K. Venayagamoorthy, "Optimal STATCOM Sizing and Placement Using Particle Swarm Optimization," Electrical and Computer Engineering Faculty Reseach \& Creative Works, 2006.

[43] O. Techniques, "Optimal Placement and Sizing of STATCOMs in Power Systems using Heuristic Optimal Placement and Sizing of STATCOM in Power Systems Using Heuristic Optimization Techniques,” pp. 437-476, 2014.

[44] R. Dubey, "Optimal Placement of Shunt FACTS Devices Using Heuristic Optimization Techniques: An Overview," 2014 Fourth International Conference on Communication Systems and Network Technologies, Bhopal, pp. 518-523, 2014.

[45] A. Fughar, "Optimal Location of STATCOM in Nigerian 330kv Networkusing Ant Colony Optimization MetaHeuristic," Global Journal of Research In Engineering, vol. 14, no. 3, 2014.

[46] R. M. J and S. E. A. Stephen, "A Critical Study On Ten Non- Traditional Optimization Methods In Solving Engineering Problems," International Journal of Mechanical Engineering and Technology, vol. 9, no. 11, pp. 233-249, 2018.

[47] S. R. Paital, P. K. Ray, and A. Mohanty, "Swarm and BAT Algorithm Optimized 2DOF-FOPID Based STATCOM Controller for Transient Stability Enhancement," 2017 Progress in Electromagnetics Research Symposium - Fall (PIERS - FALL), Singapore, pp. 1961-1968, 2017.

[48] G. Naveen Kumar, M. Surya Kalavathi, R. Harini Krishna "O Ptimal P Lacement Of Svc And Statcom For V Oltage S Tability E Nhancement Under," International Journal of Advances in Engineering \& Technology, vol. 5, no. 1, pp. 436-447, 2012.

[49] G. Choudhary and N. Singhal, "Optimal placement of STATCOM for improving voltage profile and reducing losses using crow search algorithm," 2016 International Conference on Control, Computing, Communication and Materials (ICCCCM), Allahbad, pp. 1-6, 2016.

[50] K. N. Nusair and M. I. Alomoush, "Optimal reactive power dispatch using teaching learning based optimization algorithm with consideration of FACTS device STATCOM" 2017 10th Jordanian International Electrical and Electronics Engineering Conference (JIEEEC), Amman, pp. 1-12, 2017.

[51] S. Tang, H. Yang, R. Zhao, and X. Geng, "Influence of battery energy storage system on steady state stability of power system," 2009 International Conference on Electrical Machines and Systems, Tokyo, pp. 1-4, 2009.

[52] W. Zhang, F. Li, and L. M. Tolbert, "Optimal allocation of shunt dynamic Var source SVC and STATCOM: A Survey," 2006

[53] Sujita G. V. N, B. Narasimha Reddy "Improving the loadability of the wind integrated power system using STATCOM placed at an optimal location,"International Journal of Innovative Research in Electrical, Electronics, Instrumentation and Control Engineering, , vol. 3, no. 1, pp. 114-118, 2015.

[54] K. M. Lin, W. Swe, and P. L. Swe, "Coordinated Design of PSS and STATCOM for Power System Stability Improvement Using Bacteria Foraging Algorithm," International Journal of Electrical, Computer, Electronics and Communication Engineering vo. 7, no. 2, pp. 839-846, 2013.

[55] S. Dixit and L. Srivastava, "Optimal Location and Sizing of STATCOM for Minimizing Power Loss and Improving Voltage Profile using GA,” vol. 4, no. 1, pp. 1-11, 2014.

[56] N. Altin, "Energy storage systems and power system stability," 2016 International Smart Grid Workshop and Certificate Program (ISGWCP), Istanbul, pp. 1-7, 2016.

[57] A. S. Telang and P. P. Bedekar, "Application of Voltage Stability Indices for Proper Placement of STATCOM under Load Increase Scenario," International Journal of Energy and Power Engineering, vol. 10, no. 7, pp. 998-1003, 2016.

[58] M. R. Shaik and A. S. Reddy, "algorithm to improve Voltage Stability in Power Systems," 2016 Int. Conf. Signal Process. Commun. Power Embed. Syst., pp. 648-652, 2016.

[59] P. Rao, M. L. Crow and Z. Yang, "STATCOM control for power system voltage control applications, " in IEEE Transactions on Power Delivery," vol. 15, no. 4, pp. 1311-1317, Oct 2000.

[60] R. Agrawal, S. Univesity, P. Kothari, and F. Logic, "Simulation Tool For Facts Controllers- "A REVIEW "," International Journal of Development Research, vol. 6, no. 4, pp. 7409-7416, 2016. 